\title{
LA PATAGONIA EN CLAVE REGIONAL: UN CAMINO POSIBLE PARA UNA HISTORIOGRAFÍA RENOVADA*
}

\author{
Patagonia in regional key: \\ a possible path for a historiographic renewal
}

Susana O. Bandieri ${ }^{* *}$

\section{Resumen}

Este texto pretende sintetizar los aportes que desde la investigación histórica regional se han realizado acerca de la Patagonia en los últimos años, permitiendo revisar antiguos mitos de la historiografía nacional acerca de la región y aportando miradas más complejas y diversificadas, tanto las referidas al mundo indígena y a su funcionamiento, como a la supervivencia de los antiguos circuitos mercantiles con el área del Pacífico y a los diversos poblamientos que caracterizaron su ocupación. Asimismo, se mostrarán las formas particularmente tardías de penetración estatal en diversas cuestiones que demoraron la sostenida intención política de "argentinizar" el territorio.

$$
<\text { Región }><\text { Patagonia }><\text { renovación }><\text { historiográfica }>
$$

\begin{abstract}
This paper aims to synthesize the contributions that regional historical research has made about Patagonia in recent years. Ancient myths of national historiography about the region are revised and more complex and diversified looks are provided, both referring to the indigenous world and its operation, and the survival of ancient commercial circuits with the Pacific area and the various settlements that characterized its occupation. Besides, particularly late forms of state penetration will be displayed in various issues that delayed the sustained political will to "Argentinize" the territory.
\end{abstract}

$<$ Region $><$ Patagonia $><$ historiographic $><$ renewal $>$

Recibido: 03/09/2015 // Aceptado: 06/11/2015

\footnotetext{
* Este texto reproduce la conferencia de la autora dictada en el marco de la Especialización en Historia Regional, UNNE, Resistencia, noviembre de 2013.

** Dra. en Historia, Investigadora Principal, CONICET, Universidad Nacional del Comahue, Responsable del Nodo Comahue de la Unidad Ejecutora en Red ISHIR-CONICET susana.bandieri@gmail.com
} 
"Transcurrieron dos meses sin que viéramos ningún habitante
del país. Un día, cuando menos lo esperábamos, un hombre
de estatura gigantesca se presentó ante nosotros. Estaba
sobre la arena casi desnudo, y cantaba y danzaba al mismo
tiempo, echándose polvo sobre la cabeza [...] Este hombre
era tan grande que nuestra cabeza llegaba apenas a su cintura
[...] Nuestro capitán llamó a este pueblo patagones" (Antonio
Pigafetta, Relazione del primo viaggio intorno al mondo, 1524)

Así escribía, no sin una alta dosis de exageración, el cronista de la expedición de Hernando de Magallanes, Antonio Pigafetta, uno de los dieciocho sobrevivientes que completó la vuelta al mundo regresando a España luego de atravesar el estrecho que unía ambos océanos, conocido con el nombre de su presunto descubridor -si olvidamos por cierto el conocimiento que de él tenían los habitantes del lugar-. Numerosas disquisiciones se han hecho con respecto al significado de tal denominación, que no viene al caso detallar ahora. Pero lo cierto es que, desde entonces, el territorio habitado por tan extraños seres, conocido como Patagonia, siempre fue objeto de variadas interpretaciones.

En primer lugar, por parte de los primeros viajeros y cronistas, aquellos que describieron las características de sus costas pero que pocas veces se aventuraron en su interior desconocido, que se imaginaba poblado de seres mitológicos y fantásticos. La percepción de un continente estéril, tal y como lo describiera Darwin, ${ }^{1}$ el naturalista inglés que acompañó a Fitz Roy en alguna de sus reiteradas incursiones por los mares patagónicos, se instaló en el imaginario de la época y, curiosamente, perduró y perdura, no pocas veces, cada vez que se vincula a la Patagonia con la idea de "desierto". Campaña al "desierto" se llamaron, y todavía se llaman en algunos manuales escolares, las guerras de conquista que el Estado argentino realizó sobre estos territorios en la segunda mitad del siglo XIX, hasta entonces ocupados por las sociedades indígenas. Un "desierto" que, cabe aclararlo, no se pensaba como vacío de pobladores sino como vacío de "civilización".

Debemos mencionar también algunas obras clásicas, de carácter más general, que a mediados del siglo XX se escribieron sobre la región, como las de Ricardo Caillet Bois o Armando Braun Menéndez, entre otras, donde la Patagonia aparecía, acorde a una tendencia dominante por entonces, encerrada en los límites del Estado-Nación, y la frontera argentino-chilena se visualizaba más como un espacio de conflicto que como un área de interacción.

Siguieron luego las historias de provincias, en gran parte incentivadas por la aparición de una colección muy importante de la Editorial Plus Ultra, que justamente apuntaba a ese propósito. Cabe citar, como ejemplos, para el caso de Tierra del Fuego, la obra de Arnoldo Canclini (1980), o la referida al ámbito chubutense de Clemente

\footnotetext{
1 “...sobre esta tierra pesa la maldición de la esterilidad” (Darwin, 1839: 91).
} 
Dumraut (1992). En estos casos, los límites políticos provinciales aparecían también como límites de la construcción historiográfica regional. Tema complejo si se tiene en cuenta que los mismos se correspondieron, en el caso de los antiguos territorios nacionales patagónicos, con accidentes geográficos como ríos y cordilleras o con líneas convencionales como paralelos y meridianos, más que con un conocimiento efectivo y real de la región que se pretendía recortar. Este encuadre, si bien útil para tratamientos político-institucionales, se mostraba sin duda poco apto para la comprensión de los fenómenos económicos, sociales y culturales que siempre exceden los espacios jurisdiccionales y administrativos.

Por otra parte, hace poco más de veinte años que la historia indígena comenzó a ser motivo de preocupación entre los historiadores. Las primeras obras de Mandrini (1986; 1992) y Varela y Bizet (1993), entre otros, a los cuales se agregarían luego muchísimos trabajos producidos sobre y desde la Patagonia misma, comenzaron a romper con la fragmentación epistemológica que hizo de la Arqueología, la Antropología y la Historia campos disciplinares autónomos e independientes. Otras producciones referidas a la etapa post-conquista se agregaron a éstas y la historiografía patagónica se renovó y complejizó en los últimos años.

Varios son los mitos de la historia patagónica que, a mi juicio, se corrigieron con estas nuevas investigaciones. Un primer punto se relaciona con la presunta existencia de una "frontera interna" que, cual límite físico, separaba al mundo indígena del hispanocriollo. Hoy son muchísimas las producciones que revisan exhaustivamente esta idea, mostrando que no solo el conflicto sino que también, y particularmente, el intercambio de bienes y personas, eran características propias de ese espacio fronterizo; en tanto se revela una organización político-económica de las sociedades indígenas mucho más compleja que la simple caracterización de grupos nómades dedicados exclusivamente al saqueo, la caza y la recolección.

Un segundo mito se vincula con la idea de que el límite entre los Estados nacionales argentino y chileno, constituido por la cordillera de los Andes, funcionó como tal para las sociedades involucradas antes y, sobre todo, después, de la conquista por las armas de los espacios indígenas. Hoy sabemos que las relaciones de todo tipo entre las áreas andinas de la Patagonia argentina y el sur chileno fueron comunes desde tiempos muy remotos y perduraron luego de 1880 , con similares características y viejos y nuevos actores -vinculados ahora a las formas capitalistas de producción- hasta avanzado el siglo XX.

Una Patagonia poblada exclusivamente desde el Atlántico es otra de las creencias generalizadas que quienes hacemos historia regional hemos revisado. Si bien es cierto que los territorios con puertos sobre el océano Atlántico incorporaron rápidamente la producción ovina de la meseta patagónica a una economía agroexportadora en expansión, no lo es menos que las áreas andinas siguieron manteniendo los antiguos intercambios económicos y sociales con los mercados trasandinos, a quienes proveían de carne vacuna y otros subproductos para la fabricación de suelas, tasajo, velas y jabón, que Chile utilizaba para su consumo interno o para su exportación a otras repúblicas 
Bandieri. La Patagonia en clave regional: un camino posible para una historiografía renovada.

sudamericanas con puertos sobre el Pacífico sur. Esto se acompañaba de importantes flujos migratorios de población de ese origen que traspasaba permanentemente la cordillera en busca de superficies libres para ocupar o de mejores posibilidades de trabajo, en tanto que eran comunes las inversiones de capital chileno en tierras del oriente cordillerano.

La imagen de un Estado nacional tempranamente exitoso en su penetración en los espacios ganados al indio que suele mostrar la historiografía tradicional, debe también revisarse a la luz de las nuevas investigaciones. Sin duda así lo fue en lo que hace a las modalidades de penetración coactiva o represiva frente a las sociedades indígenas, como así también a la presencia de agencias estatales destinadas a la administración de justicia y al disciplinamiento social, pero la ausencia estatal fue evidente en otros aspectos, tanto referidos a las condiciones materiales de vida de la población como a la inserción firme de una liturgia nacional, por ejemplo a través de una significativa ausencia educativa, hasta las décadas de 1930 y 40, cuando la preocupación por "argentinizar" la Patagonia se volvió esencial para los gobiernos de corte nacionalista que por entonces dominaban el escenario político nacional (Bandieri, 2009).

Todo esto indica, por de pronto, la necesidad de revisar las periodizaciones todavía vigentes en la historiografía nacional con respecto a considerar a los años 1880 como un hito fundamental en la conformación definitiva de un Estado nacional y, en consecuencia, de un mercado interno plenamente constituido, con lo cual se habrían cortado definitivamente los vínculos que distintas regiones del país mantenían con los espacios limítrofes. ${ }^{2}$ Nada más lejos de la realidad para las áreas andinas, no solo de la Patagonia, sino del conjunto nacional, marginales y periféricas al proceso de integración del país al modelo agroexportador, con clara orientación Atlántica, como se verá más adelante.

Esta y otras periodizaciones del pasado nacional son imágenes básicas que han arraigado en el sentido común de los argentinos y también, por qué no decirlo, en el de muchos educadores. Lo mismo ocurre con los contornos territoriales que el relato de ese mismo pasado encierra. Nos referimos, particularmente, a la construcción de una historia encerrada en los límites actuales del Estado argentino. Llama la atención, no obstante, la notable supervivencia de estas mismas cuestiones en parte del ámbito académico actual, especialmente en las representaciones cartográficas, que muestran escasísimos vínculos del área rioplatense con los espacios fronterizos, tanto en la etapa colonial como en las primeras décadas del siglo XIX. Las mismas representaciones cartográficas, que usamos incluso en las aulas, marcan claramente hasta 1880 la presencia de áreas caracterizadas como "territorios indígenas" que no muestran relación alguna con el conjunto espacial que se pretende mostrar, fortaleciendo así la idea de la persistencia de "espacios vacíos", tanto en el nordeste como en el sur del país.

\footnotetext{
2 Sólo a modo de ejemplo de una tendencia interpretativa dominante, mencionaremos el artículo de J. L. Ossona (1992: 69). donde se atribuye a la expansión ferroviaria de los años 1860 y 70 un efecto contundente en la reorientación "... hacia el Atlántico de todas las regiones argentinas, revistiendo las tendencias centrífugas y operando una unificación económica que sentó las bases para la formación de un mercado nacional".
} 
Esto amerita algunas reflexiones. Seguramente muchos repiten estas versiones tradicionales porque comulgan con tal interpretación de la historia nacional. Pero, en otros casos, resulta absolutamente dudoso de que se trate de esos motivos. Parece haber mucho de ingenuidad en los historiadores cuando usamos los mapas e imágenes con un sentido absolutamente ilustrativo, sin detenernos a analizar los preconceptos que tales elementos contienen. Tal vez cabría recuperar, para estos casos, la noción de "saber olvidado" de Max Scheler, es decir, lo que queda en el fondo de nuestra conciencia una vez que olvidamos los contenidos específicos que aquellas nociones portaban (Romero, coord., 2004:18).

Podrían sumarse a estos una cantidad infinita de ejemplos. Por citar sólo algunos: se sigue mostrando una sociedad argentina esencialmente blanca, con fuertes componentes europeos por efectos de la inmigración masiva, lo cual supone una invisibilización de las sociedades indígenas y mestizas sobrevivientes; así como se ubica en 1912, con el dictado de la ley Sáenz Peña del voto secreto y obligatorio, el fin de la fórmula alberdiana de la "república posible", atribuyéndole a esta norma la categoría de universal aunque excluya a las mujeres y a los habitantes de los Territorios Nacionales, que recién se convirtieron en ciudadanos plenos de la nación a mediados de la década de 1950.

\section{Los aportes de la historiografía regional}

Cuando comenzamos a realizar investigación histórica regional de manera más sistemática, allá por mediados de la década de 1980, también lo hacíamos imbuidos de algunos preconceptos sólidamente instalados en la bibliografía local y muchas veces incorporados en la documentación oficial. Partíamos en principio de hacer una historia de Neuquén encerrada en los límites del antiguo Territorio Nacional, luego Provincia de igual nombre.

Aunque no desconocíamos los importantes vínculos socioeconómicos existentes entre las sociedades indígenas y las hispano-criollas, que articulaban al norte de la Patagonia argentina con el sur chileno desde tiempos inmemoriales, antes de que los Estados nacionales se definieran como tales, entendíamos que la llegada del ferrocarril al vértice oriental del territorio y el consecuente cambio de la capital desde Chos Malal, en el norte neuquino, a ese punto, en el año 1904, había reorientado definitivamente el funcionamiento socio-económico de la región hacia el Atlántico. La misma documentación oficial así parecía indicarlo. ${ }^{3}$

\footnotetext{
3 El entonces Ministro del Interior, Joaquín V. González, justificaba de esta manera la medida: “... me ha traído al convencimiento de que la capital del Neuquén debe levantarse en el amplio valle que comienza al pasar el río. Si bien es cierto que esta posición no es materialmente central con respecto al territorio, es en cambio de alta significación económica y política, primero porque consulta los agentes más poderosos de civilización actual y segundo porque en vez de impulsar el comercio de adentro hacia afuera, como sucede hoy, lo incluirá fuertemente de afuera para adentro, siguiendo las corrientes centrípetas auxiliadas por vías férreas y fluviales que concurren al Atlántico con su gran puerto de Bahía Blanca..." (Archivo Histórico Provincial, Neuquén, Libro Copiador T/1904, Telegrama del Ministro del Interior al Gobernador de Neuquén, Carlos Bouquet Roldán, del 7-4-1904).
} 
Con el avance de nuestras investigaciones pronto descubrimos que el centro socio económico regional, pese a los buenos deseos del Ministro del Interior, seguía estando en las áreas andinas, lo cual era fácilmente comprobable en diversas fuentes documentales cualitativas y cuantitativas. Esto nos llevó en primer término a trabajar en la reconstrucción de los circuitos mercantiles y a comprobar la supervivencia de las antiguas formas indígenas de comercialización del ganado regional en el mercado chileno. En un claro ejemplo de economías complementarias, mientras el área de cría se encontraba en el oriente cordillerano, la transformación, el consumo y la comercialización se efectuaban en las ciudades y puertos del Pacífico Sur. Por supuesto que la llegada del ferrocarril a la nueva capital de Neuquén a principios del siglo XX había introducido cambios, pero estos no habían afectado en demasía el funcionamiento tradicional de las áreas andinas. La pregunta era entonces ¿hasta cuándo habían durado estas formas tradicionales del funcionamiento socio-económico regional? Futuros avances en la investigación indicaron que recién alrededor de los años 1930 ambos Estados, argentino y chileno, habían comenzado a tomar medidas arancelarias y a colocar límites al comercio cordillerano de ganado, que se habría cortado definitivamente, al menos en términos legales, en la segunda posguerra. La hipótesis que entonces manejamos era que la crisis del modelo agroexportador y la profundización de la etapa sustitutiva de importaciones habría necesitado de mercados nacionales más firmemente controlados. Esta nueva periodización, que resultaba válida para Neuquén, también lo era para otras áreas andinas productoras de ganado del país, marginales y periféricas al modelo agroexportador, tal y como demostramos con la publicación de una serie importante de trabajos de colegas argentinos y chilenos (Bandieri, coord., 2001).

La verdadera integración al mercado nacional de estas regiones habría sido entonces producto de un proceso muy largo y complejo, especialmente para los sectores de escasos recursos que antiguamente comercializaban sus animales en el mercado trasandino, y no se había producido en 1880 sino en las décadas del 1930 y 40. Más recientemente, hemos demostrado que esta periodización no solo es válida en términos económicos, sino que es aplicable a una serie importantísima de factores vinculados a la preocupación por "argentinizar" la Patagonia, preocupación por cierto no ajena a las huelgas de los obreros rurales santacruceños de la década de 1920 y a la intencionalidad de los grupos nacionalistas que desde la década siguiente dominaron la política nacional. De esa manera, una serie de instituciones y agentes estatales se hicieron presentes en la Patagonia (Gendarmería, Vialidad, Parques Nacionales, escuelas de frontera, sucursales del Banco de la Nación Argentina, Yacimientos Petrolíferos Fiscales, Yacimientos Carboníferos Fiscales, etc.) consolidando una presencia estatal hasta entonces relativamente débil (Bandieri, 2009).

En el caso de la Patagonia entonces, la investigación regional sugiere una nueva periodización para una presencia estatal más definitiva, que no se corresponde con los años 1880 sino con las décadas de 1930 y 40, cuando los gobiernos de turno realmente se preocuparon por "argentinizar" los territorios del sur, lo cual también puede relacionarse con el otorgamiento del voto a sus habitantes a mediados de la década de 1950. Asimismo, 
se impone una nueva espacialización de las relaciones socio-económicas, no sujeta a los límites políticos nacionales y/o territoriales, donde la Cordillera de los Andes deje de ser una valla para convertirse en un espacio social. ${ }^{4}$ En resumen, las variables espaciotemporales se han modificado a partir de la investigación regional.

En conclusión, insistimos en la importancia de remarcar estos resultados para rectificar una historia nacional demasiado generalizante y encerrada en los límites territoriales del Estado-Nación, tarea que consideramos imprescindible de incorporar en el campo de la enseñanza de la historia. Pero, además, y esto es fundamental para quienes hacen investigación, la periodización válida para nuestros trabajos nunca debe establecerse "a priori" -porque repetiríamos aquello que estamos tratando de corregir-, sino que debe surgir como producto del propio objeto de estudio. Lo mismo con los alcances espaciales de la región, que nunca es un espacio previamente delimitado sino un sistema abierto que "empieza y termina donde empieza y termina su explicación" (de Jong, 2001). Para ello hay que romper con las concepciones historiográficas tradicionales y transformar los límites en fronteras, o sea en espacios sociales construidos históricamente, de gran dinamismo y alta complejidad.

\section{Referencias bibliográficas}

Bandieri, S. (Coord.) 2001. Cruzando la cordillera... la frontera argentino-chilena como espacio social, Neuquén, Serie Publicaciones CEHIR-UNCo.

Bandieri, S. 2009. "Cuando crear una identidad nacional en los territorios patagónicos fue prioritario". En: Revista Pilquen, Sección Ciencias Sociales, Viedma, Centro Universitario Zona Atlántica -CURZA-, UNCo. Revista Digitalizada, Año XI, $\mathrm{n}^{\mathrm{o}} 11$.

Canclini, A. 1980. Historia de Tierra del Fuego, Buenos Aires, Editorial Plus Ultra.

Chesneaux, J. 1972. "La inserción de la historia en el espacio: la geopolítica". En Chesneaux, Jean, ¿Hacemos tabla rasa del pasado?, México, Siglo XXI.

Darwin, C. 1839. Viaje de un naturalista alrededor del globo, Londres, disponible en línea http//www.educar.

De Jong, G. 2001. Introducción al método regional, Neuquén, LIPAT-UNCo.

Dumraut, Clemente. 1992. Historia del Chubut, Buenos Aires, Editorial Plus Ultra.

Mandrini, R. 1986. "Reflexiones sobre el llamado 'complejo ecuestre' en la Argentina”. En Runa. Archivo para las Ciencias del Hombre, Buenos Aires, Instituto de Ciencias Antropológicas, UBA, Vol. XVI.

Mandrini, R. 1992. "Indios y fronteras en el área pampeana (siglos XVI-XIX). Balances y perspectivas". En: Anuario IEHS, Tandil, UNCPBA, n ${ }^{\circ} 7$.

\footnotetext{
4 En este sentido, seguimos a Jean Chesneaux, cuando presenta la teoría de la frontera-zona como área de aproximación y contactos económicos, sociales y culturales, en oposición a la frontera-línea, forma tradicional de tratar la frontera, o sea, como límite que demarca un territorio y divide poblaciones (1972: 180-191).
} 
Ossona, J. L. 1992. "La evolución de las economías regionales en el siglo XIX". En: Rapoport, M. (Comp.) Economía e Historia. Contribuciones a la Historia Económica Argentina, Buenos Aires, Edit. Tesis.

Romero, L. A. (Coord.) 2004. La Argentina en la escuela. La idea de Nación en los textos escolares, Buenos Aires, Siglo XXI.

Varela, G.y Bizet, A. 1993. "Entre guerras, alianzas, arreos y caravanas". En: Bandieri, S., Favaro O. y Morinelli, M. Historia de Neuquén, Buenos Aires, Plus Ultra. 